\title{
Capsule Commentary on Brooks et al., Strategies Used by Older Adults with Asthma for Adherence to Inhaled Corticosteroids
}

\author{
Jigar R. Rajpura, B.Pharm, M.S. \\ Department of Pharmacy Practice, Purdue University, West Lafayette, IN, USA.
}

$\mathrm{J}$ Gen Intern Med 29(11): 1531

DOI: $10.1007 / \mathrm{s} 11606-014-2962-2$

(C) Society of General Internal Medicine 2014

$\mathrm{P}$ reviously identified factors affecting asthma therapy in older patients include decreased cognitive functioning, physical limitations, and polypharmacy due to chronic disease. The consequence is lower adherence among older compared to younger patients. ${ }^{1-4}$

Brook et al. ${ }^{5}$ assessed adherence strategies with respect to inhaled corticosteroids among older asthmatic patients. Five of six identified strategies promoted adherence: keeping medications in the same location, integrating medication use with a daily routine, taking the medicine at a specific time or with other medications and using reminders, either prompting by someone else, written reminders or setting alarms. One strategy was associated with reduced adherence: taking the medication only as needed. After controlling for other variables, keeping medication in the bathroom and integrating medications as a part of a daily routine improved adherence threefold, whereas the strategy of using medication only when needed reduced adherence among study participants.

The study strength involves employing a multi-faceted approach in evaluation of adherence patterns in older adults taking inhaled corticosteroids for asthma management. The study provides a number of lessons that clinicians can use while counseling their own patients, such as discussing the identified helpful strategies with patients in addition to other commonly used methods, such as simplifying regimens and educating patients about the importance of adherence. Specifically, suggesting that the medication be kept in the bathroom rather than at the bedside, taking the medication at a designated time of day and integrating medication with their morning routine (such as when they brush their teeth) may improve adherence in older patients.

The findings from the study are limited by the subjects being female in majority, and by their being a convenience sample from two specific locations (New York and Chicago). Additional research assessing a larger population, exploring adherence strategies across different routes of treatment administrations, may prove to be clinically significant to clinical researchers and investigators in identifying employed treatment strategies.

Conflict of Interest: The author has no conflict with any of the material in this manuscript.

Corresponding Author: Jigar R. Rajpura, B.Pharm, M.S.; Department of Pharmacy Practice Purdue University, West Lafayette, IN 47906, USA (e-mail:jrajpura@purdue.edu).

\section{REFERENCES}

1. Kazis LE, Friedman RH. Improving medication compliance in the elderly. Strategies for the health care provider. J Am Geriatr Soc. 1988;36(12):11612.

2. Talreja N, Baptist AP. Effect of age on asthma control: results from the National Asthma Survey. Ann Allergy Asthma Immunol. 2011;106(1):24-9.

3. Plaza V, Serra-Batlles J, Ferrer M, Morejon E. Quality of life and economic features in elderly asthmatics. Respiration. 2000;67(1):65-70.

4. Banerji A, Clark S, Afilalo M, Blanda MP, Cydulka RK, Camargo CA Jr. Prospective multicenter study of acute asthma in younger versus older adults presenting to the emergency department. J Am Geriatr Soc. 2006;54(1):48-55.

5. Brooks TL, Leventhal H, Wolf MS, O'Conor R, Morillo J, Martynenko M, Wisnivesky JP, Federman AD. Strategies used by older adults with asthma for adherence to inhaled corticosteroids. J Gen Intern Med. 2014. doi:10.1007/s11606-014-2940-8.

Published online August 23, 2014 